Www.jmscr.igmpublication.org

Impact Factor (SJIF): 6.379

Index Copernicus Value: 79.54

ISSN (e)-2347-176x ISSN (p) 2455-0450

crossrefDOI: https://dx.doi.org/10.18535/jmscr/v6i8.177

Journal Of Medical Science And Clinical Research

IGM Publication

An Official Publication of IGM Publication

\title{
Influence of co-morbid conditions on mortality in chronic kidney disease patients in Telangana region
}

\author{
Authors \\ M.Bhavani $^{1}$, K. Vijay Kumar ${ }^{1}$, P.Kishore ${ }^{1}$, M.Venkataramana ${ }^{2}$, D.Sudheer Kumar ${ }^{3}$, \\ S.Umar Farooq ${ }^{*}$ \\ ${ }^{1}$ Department of Pharmacy Practice, Care College of Pharmacy, Oglapur (V), Damera (M), Warangal \\ (Rural), Telangana- 506006, India \\ ${ }^{2}$ Nephrologist, SVR Multispecialty hospital, Hanumakonda, Warangal, Telangana- 506006, India \\ ${ }^{3}$ Department of Pharmaceutics, Care College of Pharmacy, Oglapur (V), Damera (M), Warangal (Rural), \\ Telangana- 506006, India \\ *Corresponding Author
}

\section{S. Umar Farooq}

Department of Pharmacy Practice, Care College of Pharmacy, Oglapur (V), Damera (M), Warangal (Rural),

Telangana- 506006, India

Email: suf.pharmacist@gmail.com

\begin{abstract}
Chronic kidney disease (CKD) is a condition characterized by a gradual loss of kidney function for a long period of time. It is a worldwide public health problem with an increasing incidence and prevalence. If chronic kidney disease gets worse it may develop complications like high blood pressure, anaemia, lung disease and cardiovascular problems. The objective of this study was to find out mortality rate in nephrology department and to observe the major co-morbid conditions leading to progression of chronic kidney disease and end stage renal disease. A total of 480 patients diagnosed with CKD were enrolled in the study and we observed mortality in 80 patients (16.6\%) and the highest prevalence was observed in age group of 51-60 years. In our study, majority of the mortality cases were observed in patients with diabetes and hypertension. $85 \%$ of patients were on haemodialysis; among them most of the patients were rural residents. This study concludes that CKD is also one of the leading causes of mortality. Central and state authorities must take necessary steps in creating awareness and increase dialysis centres at the rural level, which will significantly reduce the mortality rate and improve quality of life.

Keywords: Chronic kidney disease (CKD), Mortality, Haemodialysis, Co-morbid conditions.
\end{abstract}

\section{Introduction}

CKD is defined as the presence of kidney damage, manifested by abnormal albumin excretion or decreased kidney function, quantified by measured or estimated glomerular filtration rate (GFR). ${ }^{1}$ CKD is classified by eGFR from stage 1 to stage 5, stage 1 eGFR being more than 90 $\mathrm{ml} / \mathrm{min}$ and with other renal abnormality such as proteinuria. Stage 2 eGFR is between $60-90$ $\mathrm{ml} / \mathrm{min}$, stage $3(30-60 \mathrm{ml} / \mathrm{min})$, stage 4 (15 - 30 $\mathrm{ml} / \mathrm{min}$ ), and in stage 5 (below $15 \mathrm{ml} / \mathrm{min}$ ) respectively. ${ }^{2}$ Diabetes mellitus, hypertension, 
polycystic kidney disease, systemic infections, urinary tract infections, urinary stones, lower urinary tract obstructions and drug toxicity are the causative factors. ${ }^{3}$ Uncontrolled diabetes if left untreated causes capillary and tubular basement membrane thickening, glomerular changes include loss of endothelial fenestrations, mesangial matrix expansion, and loss of podocytes with effacement of foot processes. ${ }^{4}$ Uncontrolled hypertension leads to high intra-glomerular pressure, impairing glomerular filtration. Damage to the glomeruli lead to an increase in protein filtration, resulting in increased amounts of protein in the urine (microalbuminuria or proteinuria). ${ }^{5}$ There are 3 types of renal replacement therapy haemodialysis, peritoneal dialysis, renal transplantation. Haemodialysis is needed when the glomerular filtration rate falls below $15 \mathrm{ml} / \mathrm{min} / 1.73 \mathrm{~m}^{2}{ }^{2}$.

In 2015 Global Burden of Disease Study, kidney disease was the $12^{\text {th }}$ most common cause of mortality, accounting for 1.1 million deaths worldwide. Overall CKD mortality has increased by $31.7 \%$ over the last 10 years, making it one of the fastest rising major causes of death alongside diabetes and dementia. ${ }^{7} 10 \%$ of the population worldwide is affected by CKD and millions die each year because they do not have access to affordable treatment. ${ }^{8}$ In another 112 countries, many people cannot afford treatment at all, resulting in the death of over 1 million people annually from untreated kidney failure. ${ }^{9}$

\section{Objective}

The objective of the study was to find out mortality rate in nephrology department and to observe the influence of major co-morbid conditions leading to progression of chronic kidney disease.

\section{Materials and Methods}

This study is conducted in a total of 480 patients for a period of 6 months in a multispecialty hospital. It is a Prospective observational study conducted to find out the mortality rate in nephrology department.

Inclusion criteria: Patients age above 10 years.

Patients with CKD and co-morbid conditions are included.

Exclusion criteria: Out-patients, pregnant women and patients not diagnosed with kidney disease are excluded.

Study procedure: Data is obtained through direct communication with patients, care takers and collecting their past medical history, family history, social history, compliance behaviour to haemodialysis.

\section{Results}

Of 480 patients with CKD mortality rate was found to be $16.6 \%$. We observed that the most affected age group was 51-60 years (25\%) followed by 41-50 years (23.75\%) and the mean age was $57.87 \pm 15.1$ (fig 1). Highest prevalence of mortality was observed in CKD with diabetes and hypertension $(22.5 \%)$ followed by CKD with hypertension $(21.25 \%)$. Among them, majority of the patients were above 61 years $(42.5 \%)$ as shown in (table 1). Mortality associated with sepsis was found to be $61.25 \%$ (fig 2). Of 80 patients, $85 \%$ were on haemodialysis $(47.5 \%$ were irregular to dialysis followed by $37.5 \%$ were regular) and $15 \%$ were without dialysis as shown in (fig 3). The highest prevalence of mortality was observed in 3 to 6 months period $(33.75 \%)$, followed by 7 months to 1 year $(31.25 \%$ ) (table 2).

Gender wise distribution: Out of 80 patients, 50 $(62.5 \%)$ were male and $30(37.5 \%)$ were female. Area wise distribution: Of 80 patients, prevalence was higher among rural area 47 (58.75 $\%)$ than urban $33(41.25 \%)$.

GFR wise distribution: The mean GFR of 80 mortality patients was found to be $12.06 \pm 4.08$ $\mathrm{ml} / \mathrm{min}$

Social history wise distribution: Of 80 mortality, we observed that $27.5 \%$ were alcoholic and 11.25 $\%$ were smokers. 
Table 1: Mortality wise distribution according to co-morbid conditions as per age group

\begin{tabular}{|l|c|c|c|c|c|c|c|}
\hline CKD with co-morbidities & \multicolumn{7}{|c|}{ Age (in years) } \\
\hline & $10-20$ & $21-30$ & $31-40$ & $41-50$ & $51-60$ & $>61$ & Total \\
\hline DM, HTN & 0 & 0 & 1 & 3 & 3 & 11 & 18 \\
\hline DM, HTN, PULMO & 0 & 0 & 1 & 4 & 3 & 5 & 13 \\
\hline Obstructive nephropathy & 0 & 0 & 1 & 1 & 0 & 1 & 3 \\
\hline Hypertension & 0 & 1 & 2 & 4 & 4 & 6 & 17 \\
\hline HTN, DM, CARDIO & 0 & 0 & 0 & 1 & 2 & 5 & 8 \\
\hline HTN, DM, NEURO & 0 & 0 & 0 & 2 & 5 & 2 & 9 \\
\hline ARF with Sepsis & 0 & 2 & 0 & 1 & 1 & 2 & 6 \\
\hline Diabetes mellitus & 0 & 0 & 0 & 0 & 1 & 1 & 2 \\
\hline ADPKD & 0 & 0 & 0 & 0 & 1 & 1 & 2 \\
\hline Nephrotic syndrome & 1 & 1 & 0 & 0 & 0 & 0 & 2 \\
\hline Total & 1 & 4 & 5 & 16 & 20 & 34 & 80 \\
\hline
\end{tabular}

List of diseases in each division:

Pulmo - Bronchopneumonia, pulmonary edema, pleural effusion, tuberculosis.
Cardio - Left ventricular dysfunction, coronary artery disease.

Neuro - Cerebrovascular disease.

Table 2: Mortality after initiation of haemodialysis as per age group

\begin{tabular}{|l|c|c|c|c|c|c|c|c|}
\hline Initiation & \multicolumn{8}{|c|}{ Age (in years) } \\
Haemodialysis & $20-30$ & $31-40$ & $41-50$ & $51-60$ & $61-70$ & $71-80$ & $>80$ & Total \\
\hline No haemodialysis & 1 & 0 & 3 & 0 & 5 & 2 & 1 & $12(15 \%)$ \\
\hline$<3$ months & 0 & 2 & 1 & 3 & 3 & 0 & 0 & $9(11.25 \%)$ \\
\hline 3-6 months & 1 & 1 & 8 & 6 & 8 & 3 & 0 & $27(33.75 \%)$ \\
\hline 7 months -1 year & 0 & 1 & 5 & 7 & 4 & 9 & 0 & $25(31.25 \%)$ \\
\hline$>1$ year & 1 & 0 & 0 & 1 & 4 & 1 & 0 & $7(8.75 \%)$ \\
\hline Total & $\mathbf{3}$ & $\mathbf{4}$ & $\mathbf{1 6}$ & $\mathbf{1 7}$ & $\mathbf{2 4}$ & $\mathbf{1 5}$ & $\mathbf{1}$ & $\mathbf{8 0}$ \\
\hline
\end{tabular}

Total No of patients

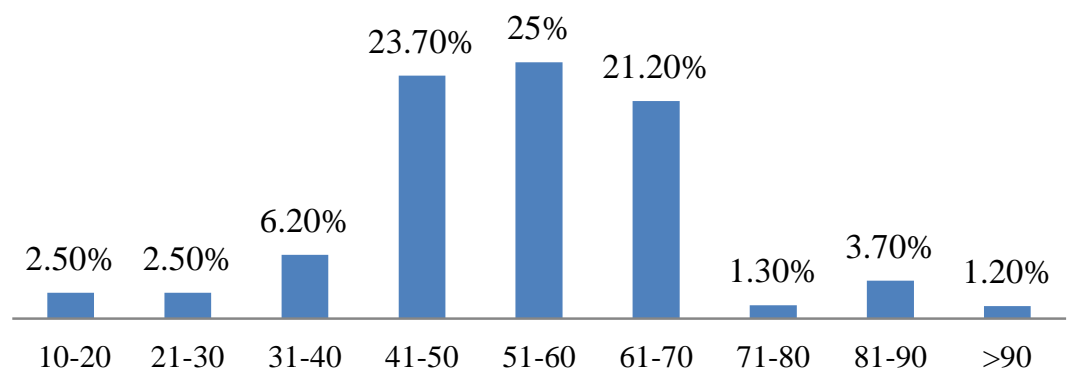

Fig 1: Age-wise distribution

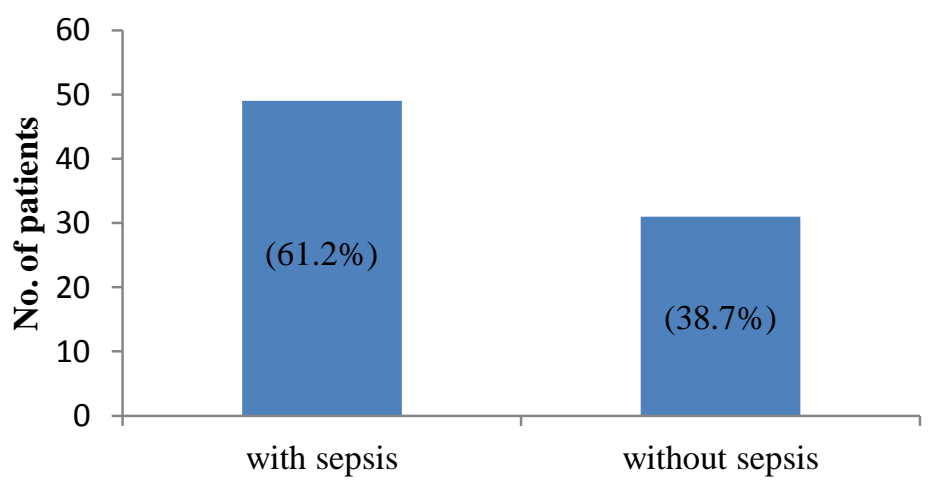

Fig 2: Distribution of data based on Mortality associated with Sepsis 


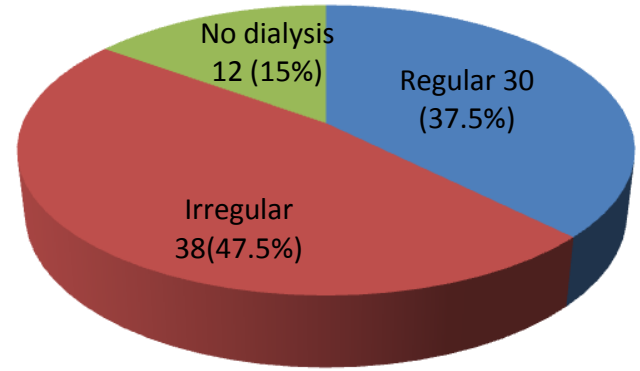

Fig 3: Distribution of data based on adherence to dialysis

\section{Discussion}

Of 480 study population, major cause of death was CKD in 80 patients, followed by other diseases and co-morbid conditions. Maria do Sameiro-Faria et al 2013, stated that mortality rate was $18.5 \% .^{10}$ that was nearly similar to our study which was found to be $16.6 \%$ and in contrast another study conducted by Mohamed Elhafiz Elsharif et al 2011, they stated that the mortality rate was $7.44 \% .^{11}$ Major reasons for mortality were multiple co-morbid conditions, rural residents and irregular haemodialysis.

Age: A study conducted by Anna J Dare et al 2017, stated that mortality rate was observed among the age group of 45- 69 years. ${ }^{12}$ Mohamed Elhafiz Elsharif et al 2011, stated that mean age of mortality was $50.44 \pm 14.17$. ${ }^{11}$ Similarly, in our study majority of mortality rate was among the age group of 51-60 years (25\%) followed by 4150 years $(23.75 \%)$ and the mean age was $57.875 \pm 15.1$. Highest mortality was observed in 51-60 years because they were suffering from multiple co-morbid conditions compared to other age groups.

Gender: A study conducted by Tamiru Shibiru et al 2013, stated that males were $46.4 \%$ and female were $42.9 \%{ }^{13}$ Percy Herrera-Anazco et al 2014, stated that males were $63.14 \%$ and females were $36.86 \% .{ }^{14}$ Similarly, in our study mortality was high in males $62.5 \%$ than females $37.5 \%$ because of their social habits like Smoking and alcohol consumption.

Co-morbid conditions: A study conducted by $\mathrm{Al}$ Wakeel JS et al 2002 stated that the leading cause of death was the cardiovascular disease in $51.7 \%$ followed by unknown/sudden death in $27.5 \%$, fluid overload, gastrointestinal hemorrhage, septicemia. ${ }^{15}$ Another study conducted by Anna J Dare et al 2017, stated that the leading cause of mortality was diabetes-34 \%, hypertension- 23 $\% .^{12}$ In contrast, to our study CKD with DM, HTN $22.5 \%$ followed by CKD with HTN 21.25 $\%$ and CKD with DM, HTN, pulmonary diseases $17.5 \%$. Highest prevalence of mortality was observed in the age group above 61 years $(42.5 \%)$ followed by 51 to 60 years $(25 \%)$. As the age increases, functioning capacity of the kidneys decrease and elderly age group people are more prone to infections because of haemodialysis. It is previously evident that uncontrolled diabetes causes mesangial expansion, podocyte effacement and intimal hyaline thickening in the blood vessels. This progresses to arterial hyalinosis of the afferent and efferent arterioles resulting in glomerular hyper filtration as stated by Stephanie TM et al 2015. Uncontrolled Hypertension leads to increased blood pressure on kidney vasculature leading to intra-glomerular pressure, impairing Glomerular filtration. ${ }^{16}$

Sepsis: A study conducted by Tamiru Shibiru et al 2013, stated that the frequently registered causes of death were septicemia $34.1 \%$ and cardiovascular diseases $29.3 \%$. $^{13}$ Another study conducted by Mohamed Elhafiz Elsharif et al 2011, stated that the leading cause of death was infections $45 \%$ and cardiovascular diseases 22 $\% .^{11}$ The national US Renal Data System (USRDS) registry reports that septicemia accounts 
for $>75 \%$ of infectious deaths. ${ }^{17}$ similarly, in our study septicemia accounts for $61.25 \%$. Type of vascular access (Jugular catheter, femoral catheter), co-morbid conditions (DM, HTN, CVDs and lung diseases), old age, and irregular dialysis were the major reasons for mortality in patients with sepsis.

Mortality after initiation of haemodialysis: Tamiru Shibiru et al 2013, stated that $45.1 \%$ deaths occurred during dialysis treatment and $23.1 \%$ of patients death occurred within the 3 months of initiation of dialysis. ${ }^{13}$ Another study conducted by Percy Herrera-Anazco et al 2014, stated that the $3^{\text {rd }}$-month mortality was $37.7 \%$ and $49.5 \%$ at 7 months. ${ }^{14}$ Similarly, in our study $33.75 \%$ mortality was observed in 3-6 months period and $31.25 \%$ during 7 months to 1 year. Highest mortality was seen between 3-6 months due to increased frequency of dialysis sessions, 3 times a week which might have lead to higher risk of infections.

GFR: A study conducted by Kim et al 2009, stated the mean eGFR as $5.8 \mathrm{ml} / \mathrm{min} / 1.73 \mathrm{~m}^{2}{ }^{18}$ another study conducted by Chang JH et al 2012, stated that mean eGFR was $8.68 \mathrm{ml} / \mathrm{min} / 1.73 \mathrm{~m}^{2}{ }^{19}$ In contrast to our study the mean GFR of mortality patients was found to be $12.06 \pm 4.80$ $\mathrm{ml} / \mathrm{min}$. The decreased GFR was due to end stage renal disease (ESRD) condition of the patients and irregular dialysis.

Based on adherence to haemodialysis: In our study, of 80 mortality patients, highest prevalence of mortality was found among irregular dialysis $47.5 \%$ patients compared to regular haemodialysis $37.5 \%$ and without any haemodialysis patients $15 \%$. Irregular to dialysis is due to the lack of awareness regarding the disease condition and knowledge regarding the importance of dialysis.

Area: A study conducted by Anna J Dare et al 2017 , stated that of total renal failure deaths in 2010-13, $68 \%$ were rural residents and $32 \%$ were urban residents. ${ }^{12}$ similarly, in our study $58.7 \%$ were rural residents and $41.25 \%$ urban residents among dialysis patients, Lack of transport facility and awareness were the reasons for irregular dialysis in rural patients.

Social habits: A study conducted by Anna J Dare et al 2017, stated that of total renal failure deaths in $2010-13,38 \%$ of the males were smokers and $38 \%$ were alcoholic. ${ }^{12}$ In contrast to our study, we observed that $27.5 \%$ of males were alcoholic and $11.25 \%$ were smokers. Smoking may also injure the kidneys by damaging the renal microvasculature through oxidative stress, reduced nitric oxide generation, and increased endothelin plasma concentration. Smokinginduced tubular cell dysfunction may further contribute to tubulo-interstitial injury and progression of CRF. ${ }^{20}$

\section{Conclusion}

Mortality rate was found to be $16.6 \%$ in the present study. Mortality was high in male than female, DM and HTN was the most associated comorbid condition with mortality of CKD patients. Rural residents were found to be more compared to urban; this is may be due to lack of awareness and transportation facilities for haemodialysis.

Availability of the clinical pharmacist in the hospital and providing services such as patient education, counseling about the renal disease, identifying the patients at risk of developing $\mathrm{CKD}$, detecting it in early stages, raising the awareness in the general public and health care workers will significantly reduce the prevalence, economic burden on patients, reduce hospital stay, reduce mortality rate and improve the quality of life among CKD patients. Government must take necessary steps in creating awareness and increase dialysis centers at the rural level, which will significantly reduce the mortality rate.

\section{Acknowledgements}

We would like to express our special thanks to all the patients who cooperated in collection of data.

\section{References}

1. Robert Thomas, Abbas Kanso, John R. Sedor. Chronic Kidney Disease and Its 
Complications. Prim Care Clin Office Pract 35 (2008) 329-344.

2. Definition of $C K D$ and classification of CKD stage. 2008 Sep; 66(9): 1645-9. Available

from www.ncbi.nlm.nih.gov/pubmed/18788389

3. Joseph T. Dipiro, Robert L. Talbert, Pharmacotherapy A Pathophysiologic Approach. Seventh Edition. Chapter 46. Chronic kidney disease: progressionmodifying therapies: Pg 747,748.

4. Radica Z. Alicic, Michele T. Rooney, and Katherine R. Tuttle, Diabetic Kidney Disease: Challenges, Progress, and Possibilities. Clin J Am Soc Nephrol 13:volume 3: 2017.

5. Leticia Buffet, Charlotte Ricchetti, Chronic Kidney Disease and Hypertension: A Destructive Combination: US Pharm. 2012; 37(6):26-29.

6. Tattersall J, Dekker F, Heimburger O, et al. When to start dialysis: updated guidance following publication of the Initiating Dialysis Early and Late (IDEAL) study. Nephrol Dial Transplant. 2011, 26:2082-2086. 10.1093/ndt/gfr168.

7. Wang H, Naghavi M, Allen C, et al., Mortality and Causes of Death Collaborators. Global, regional, and national life expectancy, all-cause mortality, and cause-specific mortality for 249 causes of death, 1980-2015: a systematic analysis for the Global Burden of Disease Study 2015. Lancet 2016: 388:1459-544.

8. Jha V, Garcia-Garcia $\mathrm{G}$, Iseki $\mathrm{K}$, et al. Chronic kidney disease: global dimension and perspectives. Lancet. Jul 20 2013: 382(9888): 260-272.

9. Couser WG, Remuzzi G, Mendis S, Tonelli M. The contribution of chronic kidney disease to the global burden of major non communicable diseases. Kidney Int. Dec 2011: 80(12): 1258-1270.
10. Maria do Sameiro-Faria, Sandra Ribeiro, Elísio Costa, et al., Risk Factors for Mortality in Hemodialysis Patients: TwoYear Follow-Up Study. Disease Markers. Volume 35 (2013), Issue 6, Pages 791798.

11. Mohamed Elhafiz Elsharif. Mortality Rate of Patients with End Stage Renal Disease on Regular Hem dialysis: A Single Center Study. Saudi J Kidney Dis Transpl 2011: 22(3): 594-596.

12. Anna J Dare, Sze Hang Fu, Jayadeep Patra, Peter S Rodriguez et al,. Renal failure deaths and their risk factors in India 2001-13: nationally representative estimates from the Million Death Study. Lancet Glob Health 2017: 5: e89-95 Vol 5.

13. Tamiru Shibiru, Esayas Kebede Gudina, Belete Habte, Amare Deribew and Tewodros Agonafer, Survival patterns of patients on maintenance hemodialysis for end stage renal disease in Ethiopia. Shibiru et al. BMC Nephrology 2013, 14:12.

14. Percy Herrera-Anazco, Vicente BenitesZapata, Adrian V. Hernandez, Edward Mezones Holguin, Manuela Silveira-Chau, Mortality in patients with chronic kidney disease undergoing haemodialysis in a public hospital of Peru. J Bras Nefrol 2015: 37(2): 192-197.

15. Al Wakeel JS, Mitwalli AH, Al Mohaya $\mathrm{S}$, Abu-Aisha H, Tarif N, Malik GH, Hammad D. Morbidity and mortality in ESRD patients on dialysis. Saudi j kidney dis transpl 2002 October-December: 13(4): 473-7.

16. Stephanie Toth- Manikowski and Mohamed G. Atta Diabetic kidney disease: Pathophysiology and therapeutic targets. Journal of diabetes research volume 2015, Article ID 697010: 1-16.

17. United States Renal Data System: USRDS 1998 Annual Data Report. Bethesda, National Institutes of Health, Diabetes and 


\title{
JMSCR Vol||06||Issue||08||Page 1060-1066||August
}

Digestive and Kidney Diseases, April, 1998.

18. Kim SG, Kim NH. The effect of residual renal function at the initiation of dialysis on patient survival. Korean $\mathrm{J}$ Intern Med 24: 2009, 55-62.

19. Chang JH, Rim MY, Sung J, et al. Early start of dialysis has no survival benefit in end-stage renal disease patients. J Korean Med Sci 27: 2012, 1177-1181.

20. Orth S.R. Smoking a renal risk factor Nephron 86: 2000, 12-26.

\author{
Abbreviations \\ ADPKD: Autosomal Dominant Polycystic Kidney \\ Disease \\ ARF: Acute Renal Failure \\ CKD: Chronic Kidney Disease \\ DM: Diabetes Mellitus \\ eGFR: Estimated Glomerular Filtration Rate \\ GFR: Glomerular Filtration Rate \\ HTN: Hypertension \\ ml/min: Millilitres/ Minute
}

